\title{
Testing the Information-Seeking Theory of Openness/Intellect
}

\author{
Hayley K. Jach, and Luke D. Smillie \\ Melbourne School of Psychological Sciences, The University of Melbourne
}

\begin{abstract}
Why are open people open? A recent theory suggests that openness/intellect reflects sensitivity to the reward value of information, but so far this has undergone few direct tests. To assess preferences for information, we constructed a novel task, adapted from information-seeking paradigms within decision science, in which participants could choose to see information related to a guessing game they had just completed. Across two studies (one exploratory, $n=151$; one confirmatory, $n=301$ ), openness/intellect did not predict information-seeking. Our results thus do not support a straightforward version of the theory, whereby open individuals display a general-purpose sensitivity to any sort of new information. However, trait curiosity (arguably a facet of openness/intellect) predicted information-seeking in both studies, and uncertainty intolerance (inversely related to openness/intellect) predicted information-seeking in Study 2. Thus, it is possible that the domain-level null association masks two divergent information-seeking pathways, one approach-motivated (curiosity), and one avoidancemotivated (uncertainty intolerance). It remains to be seen whether these conflicting motivations can be isolated, and if doing so reveals any association between information-seeking and the broader openness/intellect domain.
\end{abstract}

Keywords Openness/intellect | Information-seeking | curiosity | intolerance of uncertainty | personality processes

This manuscript has been accepted for publication at the European Journal of Personality (May 4, 2020).

This version has not been copy-edited.

Open data, materials, scripts, and pre-registration can be found at the following link: osf.io/2hjfc

$\mathbf{0}$ penness/intellect describes individual differences in the breadth, complexity, and depth of one's imagination and experience (John \& Srivastava, 1999; Schwaba, 2019). High scorers on openness/intellect tend to be curious about the world (e.g., Kashdan, Rose, \& Fincham, 2004; Kashdan et al., 2009; Kashdan et al., 2018; McCrae \& Costa, 1997), creative (McCrae, 1987), artistic (Kaufman et al., 2016), intellectual (Mussel, 2013), and intelligent (DeYoung, Quilty, Peterson, \& Gray, 2014; Kretzschmar, Spengler, Schubert, Steinmayr, \& Ziegler, 2018). Two decades ago, McCrae and Costa (1997) observed that openness/intellect is the "least researched and least understood of the five fundamental dimensions of personality" (p. 840). Since that time, there has been substantial research investigating how openness/intellect relates to attitudes and behaviors (e.g., Belke, Leder, Strobach, \& Carbon, 2010; Gosling, Ko, Mannarelli, \& Morris, 2002; Jost, Glaser, Kruglanski, \& Sulloway, 2003; Kraaykamp \& Van Eijck, 2005; Rentfrow \& Gosling, 2003), cognitive processes and abilities (Antinori, Carter, \& Smillie, 2017; Silvia, Nusbaum, Berg, Martin, \& O'Connor, 2009), and neural indices (Beaty et al., 2016; DeYoung, Peterson, \& Higgins, 2005). Further, there is a growing theoretical base concerning potential cognitive and biological processes underlying this trait (e.g., DeYoung, 2013; DeYoung, Grazioplene, \& Peterson, 2012; Kaufman et al., 2016; Mussel, 2013; Denissen \& Penke, 2008; Ziegler, Schroeter, Lüdtke, \& Roemer, 2018). To our knowledge, however, none of these theories have yet been subjected to an explicit confirmatory test.

In the present research we evaluate the evidence for one such theory that we term the information-seeking theory of openness/intellect. According to this theory, openness/intellect is grounded in greater sensitivity to the reward value of information, and thus open individuals should be more motivated to seek information (DeYoung, 2013, 2015a, 2015b). Information can be operationally defined simply as something you did not already know. This aligns with dictionary definitions of information as knowledge obtained (e.g., Merriam-Webster online dictionary), and is consistent with an abstracted version of some definitions within information theory (Shannon, 1948). Additionally, it orients information to reflect the individual's internal model of the world, rather than any external stimuli/object. For example, a book is not inherently informative; rather, a reader gains information if they are unfamiliar with the contents.

We first describe the information-seeking theory of openness/intellect and the indirect existing evidence supporting it. Next, we review paradigms used in decision science to assess information-seeking preferences in a carefully controlled manner. We then discuss the small body of research that has explored individual differences using these paradigms, identifying factors that may have influenced results from these studies. We then provide two empirical tests of the theory, the first exploratory, the second confirmatory. 


\subsection{The Information-Seeking Theory of Openness/Intellect: Summary and Current Evidence}

The information-seeking theory of openness/intellect is one part of an overarching neurobiological theory of exploratory behavior proposed by Colin DeYoung (2013). According to this theory, the neurotransmitter dopamine mediates reinforcement sensitivity, and potentiates approach behavior, to both rewards and information. DeYoung (2013) suggests that, just as the motivational value of rewards partially drives individual differences in extraversion (Depue \& Collins, 1999; Pickering \& Gray, 2001; Rammsayer, 1998), the motivational value of information partially drives individual differences in openness/intellect. This would mean that individuals scoring higher on openness/intellect should be (a) more sensitive to the reward value of information, and (b) more motivated to seek out information.

What evidence supports the information-seeking theory of openness/intellect? One might argue that clear evidence already exists: after all, people higher in openness/intellect undertake more years of formal education, visit art galleries more frequently, and consume and own a greater volume and variety of books, music, film, and other artifacts of culture (Chamorro-Premuzic, Reimers, Hsu, \& Ahmetoglu, 2011; Gosling et al., 2002; Trapp \& Ziegler, 2019; Van Eijck \& Graaf, 2004). However, these observations are simply part of our descriptions of what it means to be open: most openness/intellect scales include items which refer directly to such behaviors and interests (e.g., is fascinated by art, music, or literature, Soto \& John, 2017). In contrast, we are seeking an explanation for these descriptions-to identify what makes open people open. It is circular to treat books, plays, and culture as examples of information-seeking, and then conclude that information-seeking does indeed underpin openness/intellect. Moreover, people may seek out these stimuli for reasons that have little to do with the reward value of information. For instance, one may visit galleries to signal status or sophistication to others, or collect cultural artifacts as a financial investment. To effectively test the information-seeking theory of openness/intellect, we must use stimuli that are not inherently attractive to people higher in openness/intellect, and that are not useful to achieve goals beyond information gains.

A second argument linking openness/intellect to information-seeking is the connection to curiosity and related traits (e.g., interest, need for cognition). Curiosity can be defined as the motivation to pursue what is new, unknown, and/or complex, and is sometimes conceptualized in terms of the drive to gain information, or fill an "information gap" (Lowenstein, 1994). Curiosity is strongly correlated with openness/intellect (e.g., Kashdan et al., 2004; Kashdan et al., 2009; Kashdan et al., 2018), and has been conceptualized as a narrower trait within the broader openness/intellect domain (McCrae \& Costa, 1997; Woo et al., 2014). It is possible that if openness/intellect does relate to information-seeking, it could do so via higher interest and curiosity to engage with stimuli.

Several studies have examined relations between state curiosity and information-seeking, finding that when participants report being more curious about particular trivia questions, they are more willing to pay time or money to learn the answer (Kang et al., 2009; Gruber, Gelman, \& Ranganath, 2014; Ligneul, Mermillod, \& Morisseau, 2018; Marvin, \& Shohamy, 2016). As state curiosity is experienced more frequently and intensely by people higher in trait curiosity (Kashdan \& Steger, 2007), this provides tentative, but indirect, encouragement for DeYoung's (2013) theory. Conversely, other studies have administered trait measures alongside informationseeking, but these studies did not include a decision to seek information. For example, Lydon-Staley, Zhou, Blevins, Zurn, and Bassett (2019) asked participants to explore Wikipedia for 21 days and found that different facets of curiosity mapped onto different information-seeking strategies. Although these findings may reveal how people seek information, they don't directly address whether curious people are more likely to read Wikipedia articles in the first place. Another study measured experiences of interest in daily life, presumably across many situations in which information gain was possible (Ziegler et al., 2018). Although most interests were those we already know are attractive to individuals higher in openness/intellect (e.g., artistic interests), both state and trait openness/intellect predicted one item describing broad exploratory interests. Again, this finding provides only indirect encouragement for the information-seeking theory of openness/intellect, as exploratory intentions, not exploratory behavior, were assessed. One final study assessed four informationseeking paradigms in which participants browsed a website, studied trivia facts, and read articles (von Stumm, 2018). However, this study was focused on how openness/intellect relates to knowledge acquisition, not information-seeking preferences. Thus, although the study showed that openness/intellect predicted knowledge attainment in all four studies, it could not provide any evidence that open people were more motivated to seek information. Further, in all but the first study, the experimenter explicitly instructed participants to seek information, rather than measuring natural exploratory behavior; and in the final two studies, participants were incentivized for high performance. The first study allowed participants to seek information at their leisure, but the information concerned beautiful lakes, a topic that highopen individuals would likely be attracted to. Further, the author did not report whether the time spent freely viewing the site correlated with openness/intellect.

In summary, although previous research seems broadly consistent with the information-seeking theory, there does not seem to be any direct test of the prediction that people higher in openness/intellect are more willing to seek information in and of itself. What is required is a study assessing how openness/intellect-and connected traits such as curiosity-relate to information-seeking within a paradigm that (a) unambiguously assesses the decision to seek information, (b) uses stimuli other than those people high in openness/intellect tend to prefer. We now introduce methods developed in decision-science that may help to achieve this goal. 


\subsection{Information-Seeking in Decision Science}

Information-seeking has been extensively investigated by researchers within decision-science and cognitive neuroscience (e.g., Bennett et al., 2019; Bennett, Bode, Brydevall, Warren, \& Murawski, 2016; Blanchard, Hayden, \& Bromberg-Martin, 2015; Bromberg-Martin \& Hikosaka, 2009; Brydevall, Bennett, Murawski, \& Bode, 2018; Charpentier, Bromberg-Martin, \& Sharot, 2018; Kobayashi, Ravaioli, Baranès, Woodford, \& Gottlieb, 2019). These researchers directly assess the decision to seek information with tasks where participants must make a choice to view information. Further, these studies only assess the preference for non-instrumental information; that is, information that provides no increased likelihood of receiving an extrinsic reward (such as money or food) that could confound apparent preferences for information. Additionally, the information used in this research typically bears no resemblance to art, poetry, or other cultural stimuli that are referenced within measures of openness/intellect, thus avoiding any methodological circularity in our measures. Finally, information-seeking is typically assessed over tens or even hundreds of trials, which helps to minimize measurement error. Therefore, these tasks could be effective to test the informationseeking theory of openness/intellect.

One such task involves an array of cards in which the majority color among a set of five cards (colored black vs. red) determines the outcome of each trial (e.g., gain vs. no-gain, or loss vs. no-loss; Bennett et al., 2016). Participants choose to see either an informative set of cards (i.e., the set on which the trial outcome will actually be based) or an uninformative set of cards (i.e., a random selection of black and red cards that has no relation to the trial outcome). On some trials, participants must pay a small proportion of their winnings to see this advance information. No matter their choice, participants learn if they win or lose after the trial ends, making the informative cards economically non-instrumental. Despite this, participants show reliable preferences for information in this task, and there are robust individual differences in the willingness to pay to see the information (Bennett et al., 2016; Brydevall, Bennett, Murawski, \& Bode, 2018; Bennett et al., 2019).

Interestingly, the information-seeking theory of openness/intellect was partly inspired by an animal analogue of this very task (see DeYoung, 2013, pp. 4-5). Specifically, Bromberg-Martin and Hikosaka (2009) found that primates will sacrifice primary rewards (food, juice) to learn the outcome of a gamble in advance (see also Blanchard et al., 2015). These researchers found that noninstrumental information elicits release of dopamine within the brain reward system, in a similar manner to primary rewards, suggesting that information has a reward value. DeYoung (2013) grounded his conception of information rewards, to which individuals high in openness/intellect are putatively more sensitive, in these studies. Thus, if openness/intellect predicts seeking even this form of information-devoid of any aesthetic or intellectual content-this would be consistent with the existence of a general-purpose sensitivity to the reward value of information. This would provide strong evidence in favor of the information-seeking theory.
To date, three studies have directly assessed the Big 5 personality correlates of non-instrumental information-seeking using this task (Smillie, 2019, Study 1 and 2; and Bennett et al., 2019, which used the same dataset as Study 1 from Smillie, 2019). In these studies, participants were overwhelmingly likely to choose information when it was free, and individual differences emerged when participants were required to pay some small amount of money to see the informative set. However, in both studies $(N=139$ and $N=163$, respectively), correlations between openness/intellect and information-seeking were non-significant and nearzero (Study $1 r=.03$; Study $2 r=-.03$; Smillie, 2019). Conversely, measures of neuroticism and obsessivecompulsive tendencies, reported by Bennett and colleagues (2019), predicted a stronger preference to see information ( $r=.31$ and $r=.25$, respectively).

These findings fail to support a straightforward prediction that people high in openness/intellect are more motivated to seek information. However, the way in which information-seeking was operationalized might partially explain why. Specifically, information-seeking within this task entails making a choice to reduce one's uncertainty about the money that they would soon be winning or losing. As such, this form of information might be particularly suited to motivate individuals higher in trait intolerance of uncertainty. These individuals might find the lack of information aversive and subsequently seek information as a strategy to reduce their negative emotions (Carleton et al., 2012; Bennett et al., 2019). As intolerance of uncertainty correlates negatively with openness/intellect and curiosity and is strongly associated with higher neuroticism (Carleton et al., 2012; Jach \& Smillie, 2019; Kashdan et al., 2018), this may explain why neuroticism, rather than openness/intellect, was found to predict information-seeking (Bennett et al., 2019; Smillie, 2019).

\subsection{Aims of the Present Research}

Building on these recent tests of the informationseeking theory of openness/intellect, we sought to examine forms of information-seeking that do not lead to reductions in uncertainty about upcoming monetary outcomes, and thus are less likely to be motivated by intolerance of uncertainty. To achieve this, we reversed the sequence of events within the task structure employed by Bennett et al. (2016) such that participants first learn the outcome of a guessing game (win or loss) and can then seek additional information. This information concerned an inconsequential detail of the just-completed game. This information is non-instrumental as it cannot affect their monetary outcome, and because it is made available after the game, a choice to view information cannot serve to resolve uncertainty regarding the game outcome. In all other aspects, this task retains the benefits described above: it measures non-instrumental information; uses stimuli that are not, by definition, desirable to people higher on openness/intellect; and includes multiple trials. Whereas curiosity may still motivate information-seeking, aversion to uncertainty related to the monetary prize 


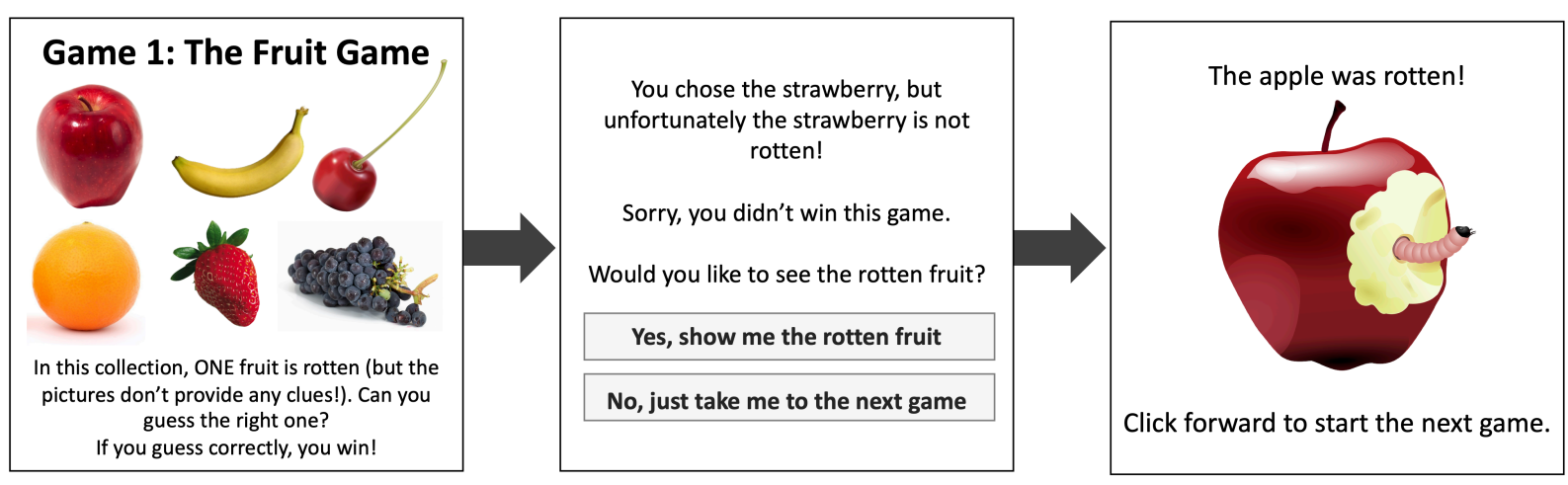

Figure 1. Behavioral information-seeking, Game 1. In this example, the participant chooses to seek information, and is shown an image of the fruit that was rotten (the apple).

should not, allowing us to assess whether openness/intellect predicts (possibly curiosity-driven) information-seeking.

Study 1 was designed to explore these potential questions. According to DeYoung's (2013) theory, we expected that openness/intellect would positively predict seeking information, and we also expected this to be the case for measures of trait curiosity. Conversely, we expected that intolerance of uncertainty would not significantly predict this form of information-seeking. Study 2 adopts a confirmatory approach, providing a preregistered test of hypotheses derived from Study 1. All study materials, deidentified data and analysis scripts for both studies, and preregistration for Study 2 are available on the Open Science Framework (project: osf.io/2hjfc/; preregistration: osf.io/fsx5e). The Supplementary Information includes a table listing our compliance to the pre-registration. Ethical approval for both studies was provided by the University of Melbourne Human Ethics Advisory Group (ID 1953559.1).

\section{Study 1}

\subsection{Method}

2.1.1 Participants and Procedure. We recruited 154 United States residents through the online marketplace Amazon Mechanical Turk (mTurk). We scaled the participant incentive to \$7.25USD per hour, the approximate US minimum wage in early 2019. This equated to a $\$ 1.00$ base payment plus $50 \mathrm{c}$ bonus for passing two simple attention checks, plus a second 50c bonus for winning the decision-making games. We excluded participants if they (a) completed less than $90 \%$ of the study, (b) had a within-person standard deviation of less than 0.50 across the Likert-scale items or a sequence of equal to or greater than 20 consecutive responses (to prevent straight-lining), or (c) failed both a comprehension check at the end of the behavioral information-seeking tasks and an attention check

1 To reduce undesirable noise assessing individual differences, each game was rigged: participants won or lost the same games, and this embedded within the surveys. After removing 3 participants for failing any of these exclusion criteria, the final sample was 151 individuals $\left(\right.$ mean $_{\text {age }}=36.68, \mathrm{SD}_{\text {age }}=$ $9.85,47 \%$ female). A sample of this size-which was determined by financial constraints-provides approximately $70 \%$ power to detect a typical effect size within the context of personality psychology $(r=.20$; Gignac \& Szodorai, 2016).

\subsubsection{Materials and Procedure.}

Behavioral Information-Seeking. We assessed information-seeking via a series of five guessing games, plus an additional information-seeking question after the games had ended, resulting in a 6-item measure of behavioral information-seeking. To motivate participants we informed them that their bonus for the experiment would be based on their performance for one randomly selected game. However, in reality, all participants were allocated the same winning amount (and were appropriately debriefed about this following the survey). For each trial, participants made a guess as to the correct answer, and were immediately told if they had won or lost that trial. 1 Following their guess and feedback, participants could choose to view non-instrumental information about an earlier stage of the game. Choosing to view this information did not change the game outcome and could not be used to inform future behavior. Additionally, choosing information required navigating to a new screen and therefore entailed a small time cost, which we believed would be salient to mTurk workers.

Game 1 (Figure 1) presented participants with a display of six fruit, and asked participants to guess which fruit was secretly rotten. After losing the game, participants were asked if they would like to know which fruit had indeed been rotten. The choice to see the rotten fruit was coded as seeking information. In Game 2, participants were told that the numbers 1 to 10 had been divided into two boxes, with one box containing the numbers 1 to 5 , and the second box containing the numbers 6 to 10. Their task was to choose a box from which one number would be drawn: a number between 1 and 5 would mean a loss, and a number between 6 and 10

deception was revealed to participants after they had completed the survey. 
would mean a win. Following their win, participants were asked if they would like to see the specific number that had been selected from the box. For Game 3 through 5 (adapted from Jach \& Smillie, 2019), participants were asked to imagine that they were explorers searching for two precious gems, chromite and zanium. In all three games, participants had to choose between two options with equal expected utility, but where one option was more ambiguous than the other. In Game 3, following their choice, they were asked whether they would like to know which gem they selected. In Game 4, participants were asked if they would like to know the exact proportion of gems in the right chest. In Game 5, participants were asked if they would like to see how many zanium gems were in the chest. These choices were coded as informationseeking.

Following the five games, participants were informed that they had won the bonus money. They were then asked if they would like to see which game was connected to winning the bonus or continue the survey without ever knowing. The choice to see this game was the final measure of information-seeking.

Big 5 personality traits. The Big Five Aspect Scales (BFAS; DeYoung, Quilty, \& Peterson, 2007), a widely-used measure of the Big Five traits and their lowerlevel aspects, was used to measure openness/intellect, neuroticism, extraversion, agreeableness, and conscientiousness. Our primary focus was on the openness/intellect domain, which divides into intellect, describing engagement with semantic and abstract information (e.g., Like to solve complex problems), and openness, describing engagement with aesthetic and perceptual information (e.g., Enjoy the beauty of nature).

Curiosity. Curiosity was assessed using the fivedimensional curiosity scale (Kashdan et al., 2018). This scale divides into five factors, two of which are particularly pertinent to the current study: joyous exploration, describing enthusiasm for exploring and leaning in general (e.g., I find it fascinating to learn new information), and deprivation sensitivity, describing an intense hunger for specific knowledge (e.g., I work relentlessly at problems that I feel must be solved). Three additional dimensions are stress tolerance (e.g., I cannot handle the stress that comes from entering uncertain situations [reversed]), social curiosity (e.g., I like to learn about the habits of others), and thrill-seeking (e.g., Risk-taking is exciting to me). The scale's factor structure, temporal stability, internal consistency, and construct validity has been supported across three studies comprising 4,000 participants.

Ambiguity and uncertainty tolerance. The Multiple Stimulus Types Ambiguity Scale-II (e.g., I am tolerant of ambiguous situations; McLain, 2009) and the intolerance of Uncertainty Scale-12 (e.g., The smallest doubt can stop me from acting; Carleton, Norton, \& Asmundson, 2007) were employed to measure ambiguity tolerance and uncertainty intolerance. Note also that the stress tolerance subscale from Kashdan and colleagues' (2018) curiosity measure can also be considered a measure of uncertainty tolerance.

2.1.3 Analyses. R version 3.5.2 (R Core team, 2018) was used for all preprocessing and analyses. Within $\mathrm{R}$, we used the following packages: tidyverse (Wickham, 2017) careless (Yentes \& Wilhelm, 2018), cowplot (Wilke, 2018), lm.beta (Behrendt, 2014), lavaan (Rosseel, 2012), apaTables (Stanley, 2018), psych (Revelle, 2018), and BayesFactor (Morey \& Rouder, 2018).

\subsection{Results}

2.2.1 Descriptive statistics. Table 1 includes the mean, standard deviation, reliability (omega total) and correlations for all variables measured. Table S2.1 includes further descriptives (median, range, skew, and kurtosis) for these variables. Information-seeking demonstrated high reliability $\left(\omega_{\mathrm{t}}=.93, \omega_{\mathrm{h}}=.77, \alpha=.87\right)$, indicating that participants were displaying consistent patterns in their choice behavior. Figure S2.1 shows the pattern of responses for each information-seeking question. Despite the cost imposed in time from choosing to see information, more than half of participants chose to view information for each question. Indeed, for Question 1, $91 \%$ of participants chose information. In total, 60 individuals $(40 \%$ of the sample) always sought information. This led to a somewhat non-normal distribution for information-seeking, with acceptable skew (-0.34) but high kurtosis (-1.50). As non-normal dependent variables can cause biased estimates of standard errors and significance tests (Coxe, West, \& Aiken, 2009), the supplementary information includes alternate analyses using Poisson regression, which yielded similar findings.

Considering interrelations between survey measures, openness/intellect was positively related to curiosity ( $r=.49,95 \%$ CI $[.36, .60])$, positively related to ambiguity tolerance $(r=.52,95 \%$ CI $[.40, .63])$, and negatively related to uncertainty intolerance $(r=-.37,95 \%$ CI [-.50, -.23]), in line with previous research (Jach \& Smillie, 2019; Kashdan et al., 2018). When assessing how openness/intellect related to sub-scales of curiosity, the strongest relationship was with joyous exploration $(r=$ $.69,95 \%$ CI $[.60, .76])$, but there were also significant relations between openness/intellect and deprivation sensitivity $(r=.20)$ and stress tolerance $(r=.39)$.

\subsubsection{Information-seeking and personality.} Information-seeking did not significantly relate to openness/intellect ( $r=-.10,95 \%$ CI $[-.25, .06])$. However, information-seeking correlated with curiosity $(r=.16$, $95 \%$ CI $[+.00, .31])$ including its subscale deprivation sensitivity ( $r=.18,95 \%$ CI $[.02, .33])$, but not the subscale joyous exploration $(r=.11,95 \%$ CI $[-.05, .27])$. Additionally, none of ambiguity tolerance, uncertainty intolerance, or stress tolerance significantly correlated with seeking information. As a lack of evidence for an effect does not provide evidence for a null effect, we employed a Bayes factor regression to assess evidence for models in which openness/intellect predicted information-seeking against a null model with flat regression slopes. Bayes factors greater than 1 provide evidence that the variables are predictors of information-seeking, whereas Bayes factors less than 1 provide evidence for the null hypothesis (Dienes, 2014). 
Table 1.

Means, Standard Deviations, Reliability, and Correlations Between Study 1 Variables

\begin{tabular}{|c|c|c|c|c|c|c|c|c|c|c|c|c|c|c|c|c|c|c|}
\hline Variable & $\omega_{\mathrm{t}}$ & $M$ & $S D$ & 1 & 2 & 3 & 4 & 5 & 6 & 7 & 8 & 9 & 10 & 11 & 12 & 13 & 14 & 15 \\
\hline 1. Information-seeking & .93 & 0.63 & 0.36 & & & & & & & & & & & & & & & \\
\hline 2. Openness/Intellect & .92 & 3.65 & 0.49 & -.10 & & & & & & & & & & & & & & \\
\hline 3. Openness & .88 & 3.44 & 0.44 & .02 & .67 & & & & & & & & & & & & & \\
\hline 4. Intellect & .91 & 3.85 & 0.75 & -.14 & .90 & .29 & & & & & & & & & & & & \\
\hline 5. Agreeableness & .93 & 3.83 & 0.64 & -.01 & .37 & .33 & .29 & & & & & & & & & & & \\
\hline 6. Conscientiousness & .92 & 3.58 & 0.67 & -.03 & .27 & -.05 & .39 & .35 & & & & & & & & & & \\
\hline 7. Neuroticism & .96 & 2.63 & 0.93 & .05 & -.36 & .12 & -.54 & -.23 & -.54 & & & & & & & & & \\
\hline 8. Extraversion & .94 & 3.22 & 0.76 & .03 & .45 & .11 & .52 & .25 & .45 & -.60 & & & & & & & & \\
\hline 9. Curiosity & .89 & 3.37 & 0.51 & .16 & .49 & .27 & .48 & .08 & .26 & -.43 & .65 & & & & & & & \\
\hline 10. Joyous exploration & .89 & 3.87 & 0.77 & .11 & .69 & .42 & .65 & .28 & .30 & -.33 & .46 & .72 & & & & & & \\
\hline $\begin{array}{l}\text { 11. Deprivation } \\
\text { sensitivity }\end{array}$ & .84 & 3.57 & 0.79 & .18 & .20 & .18 & .15 & .06 & .15 & .07 & .09 & .52 & .43 & & & & & \\
\hline 12. Stress tolerance & .91 & 3.10 & 1.07 & .00 & .39 & .00 & .50 & .16 & .34 & -.75 & .66 & .52 & .32 & -.15 & & & & \\
\hline 13. Social curiosity & .89 & 3.59 & 0.82 & .16 & .12 & .20 & .03 & .13 & .03 & .08 & .19 & .49 & .19 & .29 & -.14 & & & \\
\hline 14. Thrill seeking & .88 & 2.70 & 0.96 & .05 & .06 & .06 & .04 & -.35 & -.08 & -.16 & .38 & .66 & .25 & .14 & .25 & .21 & & \\
\hline $\begin{array}{l}\text { 15. Uncertainty } \\
\text { intolerance }\end{array}$ & .94 & 3.10 & 0.87 & .08 & -.37 & -.04 & -.46 & -.14 & -.25 & .66 & -.55 & -.42 & -.30 & .26 & -.85 & .14 & -.26 & \\
\hline 16. Ambiguity tolerance & .92 & 3.06 & 0.75 & -.06 & .52 & .18 & .57 & .10 & .18 & -.59 & .53 & .56 & .48 & -.11 & .78 & -.05 & .36 & -.86 \\
\hline
\end{tabular}

Note. $M, S D$, and $\omega_{\mathrm{t}}$ are used to represent mean, standard deviation, and internal consistency (omega total) respectively. Italics indicate $p$ $<.05$. Bold indicates $p<.01$.

The current study takes the reciprocal of values $<1$ to provide more easily interpretable results concerning support for the null, such that all Bayes factors for and against the null are 1 or greater (as such, the term $M_{01}$ indicates evidence in support of the null, whereas $M_{10}$ indicates evidence for the alternative). We follow Jeffreys $(1939 / 1961)$ who suggests conventional cut-offs with $>3$ considered substantial evidence for the alternative/reciprocal null.

For regressions predicting information-seeking from openness/intellect, weak evidence for the null was obtained $\left(\mathrm{M}_{01}=2.99\right)$, suggesting inconclusive evidence to state whether or not openness/intellect predicts information-seeking. We also used Bayes factor regressions to assess support for the null with our three scales measuring tolerance for uncertainty (ambiguity tolerance, intolerance of uncertainty, and stress tolerance) and found support for the null with all three scales measured separately $\left(\mathrm{M}_{01}=4.46,3.68\right.$, and 5.70, respectively) and even stronger support when they were all entered into the same regression equation $\left(M_{01} 13.05\right.$ in favor of the null). This tentatively suggests that our task was successful in eliciting curiosity- rather than uncertainty-driven information-seeking.

\subsection{Study 1 Interim Discussion}

In this exploratory study, we found that curiosity was related to seeking non-instrumental information, whereas multiple measures of uncertainty intolerance were not. This suggests that our new task design may have successful reduced decisions motivated by intolerance of uncertainty.

Despite the strong correlation between openness/intellect and curiosity, we did not observe that openness/intellect predicted information-seeking. However, we did not find decisive evidence against this relation, with a non-significant result and Bayes factors indicating only anecdotal evidence for the null.

There are several possible reasons for this outcome. First, although we observed a relation between information-seeking and curiosity, when broken down by facet it was significant only for the deprivation sensitivity subscale. It is possible that the design of the informationseeking task could be improved to increase the chance of tapping other factors of curiosity, such as joyous exploration. For example, we placed all informationseeking games together in the survey, which may have been repetitive and boring. Additionally, we did not explicitly tell participants that the information they could select would not be beneficial to them later in the experiment, so some participants may have suspected that the information they gained could help to win a future game. This may have explained the high numbers of people choosing to see information throughout the games, and particularly in Game 1 (around 90\%). However, this seems unlikely given that, from Game 2 onward, participants would see how different each of the games were from each other. Nevertheless, if people thought that the information might assist in future decision-making, this may have increased pragmatic decision-making.

\subsection{Aims and Hypotheses for Study 2}

For Study 2, we aimed to address the potential issues in the task outlined above. To reduce the repetitiveness of these tasks, we interspersed them between sections of the surveys. To ensure participants were aware of the non-instrumental nature of the information they could obtain, we explicitly stated that the information for a given game would not be useful in subsequent games. We also included a single informationseeking question at the end of the games in which participants could choose to immediately know if they won the bonus money, but incur a 30-second time delay before proceeding with the survey; or alternatively, wait until the end of the survey to see if they had won. Unlike in our main task, this information serves to reduce uncertainty about the potential bonus and is thus analogous to the task used by Smillie (2019) and Bennett et al. (2019). We considered that including this task alongside our main information-seeking measure may help disentangle effects of curiosity- versus uncertainty-driven information-seeking.

We hypothesized that when information-seeking was measured as it was for Study 1, openness/intellect, curiosity, and its facets deprivation sensitivity and joyous exploration would positively correlate with and predict information-seeking. We also hypothesized that 
uncertainty intolerance, ambiguity tolerance, and neuroticism would not predict information-seeking. Further, we hypothesized that neuroticism and uncertainty intolerance would positively predict our new reward-related information-seeking question; that ambiguity tolerance would negatively predict it; and that openness/intellect would not be a significant predictor. ${ }^{2}$

\section{Study 2}

\subsection{Method}

3.1.1 Participants. Participants were 316 United States residents recruited through mTurk. As we found in Study 1 that a small proportion of participants required more time to complete the study than we had expected, we increased the base study payment to $\$ 1.50$, keeping the $50 \mathrm{c}$ bonus for winning the decision-making games (which we allocated to everyone) and the 50c attention-check bonus. The target sample for this study was $N=300$. We excluded participants for the same reasons as stated in Study 1, and exclusion criteria led to the total loss of 15 participants, leaving a final study sample of 301 (mean $_{\text {age }}$ $=36.54, S D_{\text {age }}=10.30, \min =19, \max =69 ; 124$ female, 175 male, and two responding "other"). This sample provides approximately $94 \%$ power to detect a typical effect size within the context of personality psychology $(r=.20$; Gignac \& Szodorai, 2016).

3.1.2 Materials and Procedure. We used all measures from Study 1. As described above, we also included an additional single-item information-seeking question which provided temporal reduction of uncertainty about an upcoming reward. Specifically, after completing all trials of the main information-seeking task, participants were asked to choose between either (a) learning immediately if they won the bonus payment, but incurring a 30-second time penalty; or (b) waiting until the end of the experiment to learn this information, with no time penalty. Note that if participants asked to wait until the end of the study to find out their bonus, then we also waited until that time to assess the final information-seeking item from the main measure (see Section 2.1.2 for full explanation of the original trials).

3.1.3 Analysis strategy. Mean (observed) scores were used for descriptive and inferential statistics. However, the supplementary materials contain several additional companion analyses. First, as inferences concerning parameter values from multiple regression can sometimes be misleading with observed variables, we computed regressions with latent variables, which account for measurement error and typically give a better estimate of the true effect size (Westfall \& Yarkoni, 2016). Second, we computed tetrachoric factor scores for informationseeking, and conducted regular regressions with otherwise observed variables. Finally, similarly to Study 1 , our information-seeking measure was non-normal (and thus could potentially lead to incorrect Type 1 error rates; Coxe et al., 2009). We thus employed Poisson regressions as were used for Study 1. Unless otherwise stated, inferences presented in the manuscript body were consistent for each of these measures.

We used Bayes factor regressions for several of our key hypotheses from which we intended to make inferences concerning null effects. For each regression, we tested the null hypothesis that regression slopes were 0 against the alternative that all slopes were nonzero. This package uses default mixture-of-variance priors that are calculated from a version of the multivariate Cauchy distribution (see Rouder \& Morey, 2012, for a full description of this approach).

\subsection{Results}

3.2.1 Descriptive Statistics. As in Study 1, informationseeking demonstrated excellent reliability (Table 2). Figure 2 shows (A) the frequency of information-seeking for each of the 6 items separately, (B) how often each person chose to seek information, and (C) responses to the reward-related information-seeking question. A large number of participants chose to view information on the first trial, but choices were more evenly divided for the remainder of trials. Participants appeared to seek information slightly less frequently than in Study 1, perhaps as a result of our assurance that information wasn't instrumentally useful for performance. For the single-item reward-related question (Figure 2C), a majority of people chose to wait until the end of the survey to find out if they won bonus money, rather than seeking this information immediately.

Table 3 illustrates the zero-order correlations between the battery of variables. Our central informationseeking measure correlated only moderately with rewardrelated information-seeking ( $r=.28,95 \%$ CI $[.17, .38])$, suggesting that we may be tapping partially dissociable forms of information-seeking. tolerance related positively to openness/intellect and extraversion and negatively to neuroticism; and the opposite pattern of findings occurred for intolerance of uncertainty. 
Table 2.

Internal Consistency, Means, Standard Deviations, and Distribution Information for All Variables

\begin{tabular}{|c|c|c|c|c|c|c|c|c|}
\hline & $\omega_{\mathrm{t}}$ & $\omega_{\mathrm{h}}$ & Mean & $\mathrm{SD}$ & Min & Max & Skew & Kurtosis \\
\hline Information-seeking & .94 & .85 & 0.57 & 0.38 & 0 & 1 & -0.15 & -1.59 \\
\hline Reward information-seeking & NA & NA & 0.36 & 0.48 & 0 & 1 & 0.60 & -1.64 \\
\hline Openness/Intellect & .90 & .42 & 3.59 & 0.48 & 2.25 & 4.65 & -0.03 & -0.64 \\
\hline Openness & .86 & .57 & 3.41 & 0.45 & 2 & 4.6 & -0.16 & -0.08 \\
\hline Intellect & .87 & .48 & 3.78 & 0.69 & 1.6 & 5 & -0.22 & -0.46 \\
\hline Agreeableness & .93 & .69 & 3.73 & 0.67 & 2.4 & 5 & 0.09 & -1.18 \\
\hline Conscientiousness & .93 & .55 & 3.55 & 0.67 & 1.95 & 5 & 0.04 & -0.70 \\
\hline Neuroticism & .95 & .57 & 2.61 & 0.82 & 1 & 4.85 & 0.02 & -0.47 \\
\hline Extraversion & .93 & .53 & 3.21 & 0.72 & 1.15 & 4.95 & -0.25 & 0.11 \\
\hline Curiosity & .88 & .65 & 3.39 & 0.49 & 1.44 & 4.88 & -0.23 & 0.98 \\
\hline Joyous exploration & .83 & .69 & 3.90 & 0.73 & 1.2 & 5 & -0.69 & 0.40 \\
\hline Deprivation sensitivity & .80 & .70 & 3.64 & 0.79 & 1 & 5 & -0.56 & 0.04 \\
\hline Stress tolerance & .86 & .83 & 2.94 & 1.01 & 1 & 5 & 0.17 & -0.87 \\
\hline Social curiosity & .86 & .68 & 3.56 & 0.83 & 1 & 5 & -0.59 & 0.09 \\
\hline Thrill seeking & .87 & .80 & 2.94 & 1.02 & 1 & 5 & -0.12 & -0.87 \\
\hline Uncertainty intolerance & .94 & .66 & 3.23 & 0.85 & 1 & 5 & -0.22 & -0.42 \\
\hline Ambiguity tolerance & .91 & .65 & 3.02 & 0.72 & 1.23 & 5 & 0.26 & -0.05 \\
\hline
\end{tabular}

\section{a. Information seeking (by item)}
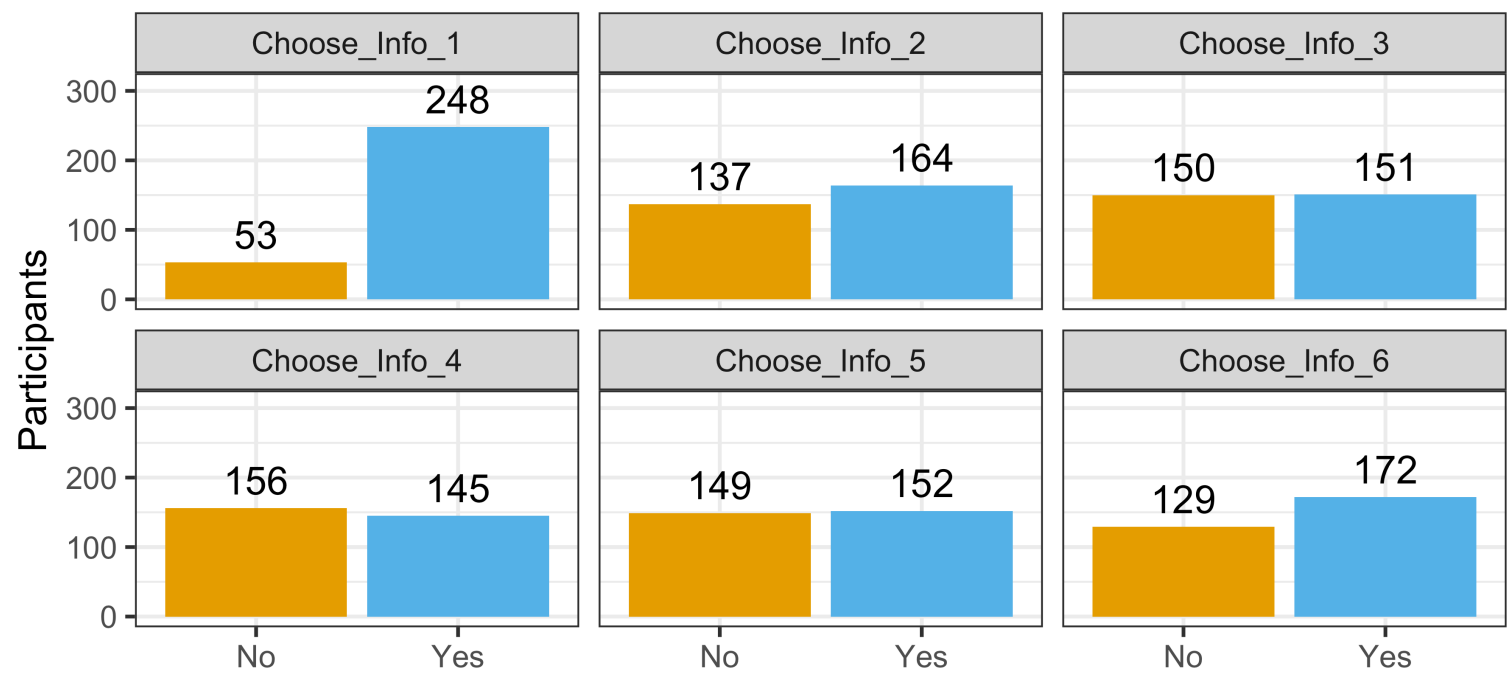

\section{b. Frequency of information seeking}

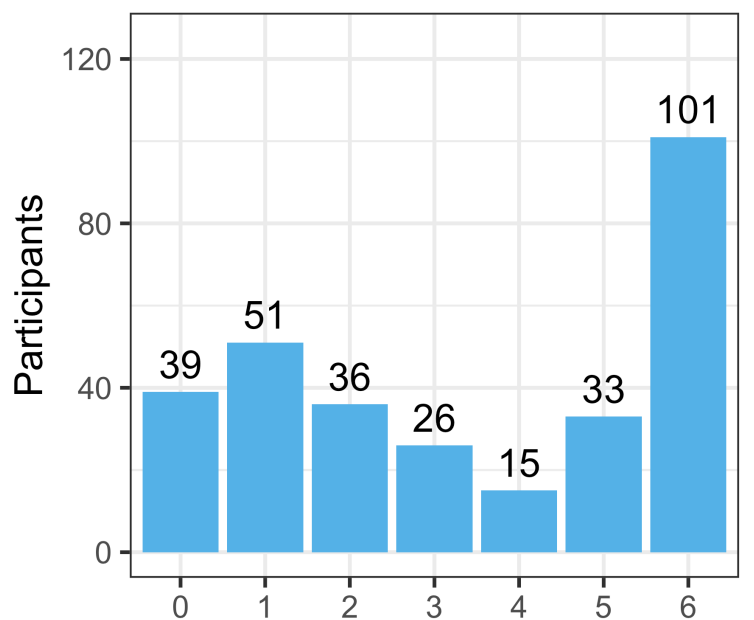

c. Reward-related information seeking

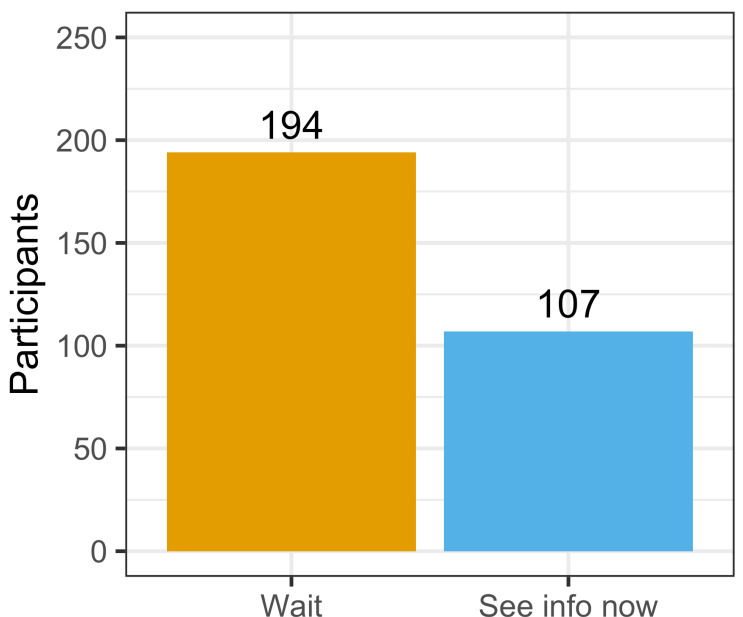

Figure 2. Responses to the customized information-seeking responses. $A$. The frequency of responses for each individual item. No = Participants chose not to view information, Yes = Participants chose to view information. Note that Choose Info 1 has a large proportion of participants choosing to view the information, but the remainder of the questions contain roughly equal responses. $B$. Frequency of times out of 6 an individual chose to see information. Roughly a third of respondents always chose to see information. $C$. Single-item information-seeking measure that reduces uncertainty about an upcoming reward. Here, most participants chose to wait rather than seek information. 
Table 3

Correlation Matrix, Study 2

\begin{tabular}{|c|c|c|c|c|c|c|c|c|c|c|c|c|c|c|c|c|}
\hline Variable & 1 & 2 & 3 & 4 & 5 & 6 & 7 & 8 & 9 & 10 & 11 & 12 & 13 & 14 & 15 & 16 \\
\hline \multicolumn{17}{|l|}{ 1. Information-seeking } \\
\hline 2. Reward information-seeking & .28 & & & & & & & & & & & & & & & \\
\hline 3. Openness/Intellect & -.05 & -.16 & & & & & & & & & & & & & & \\
\hline 4. Openness & .02 & -.10 & .75 & & & & & & & & & & & & & \\
\hline 5. Intellect & -.08 & -.16 & .91 & .40 & & & & & & & & & & & & \\
\hline 6. Agreeableness & -.12 & -.16 & .49 & .35 & .45 & & & & & & & & & & & \\
\hline 7. Conscientiousness & -.04 & -.11 & .35 & .08 & .43 & .40 & & & & & & & & & & \\
\hline 8. Neuroticism & .13 & .12 & -.35 & .02 & -.49 & -.39 & -.58 & & & & & & & & & \\
\hline 9. Extraversion & -.07 & -.03 & .40 & .17 & .44 & .15 & .43 & -.50 & & & & & & & & \\
\hline 10. Curiosity & .09 & .09 & .49 & .34 & .46 & .01 & .17 & -.19 & .52 & & & & & & & \\
\hline 11. Joyous exploration & .15 & .07 & .62 & .42 & .60 & .17 & .13 & -.18 & .34 & .75 & & & & & & \\
\hline 12. Deprivation sensitivity & .20 & .07 & .30 & .26 & .25 & -.00 & .13 & .17 & .04 & .55 & .53 & & & & & \\
\hline 13. Stress tolerance & -.21 & -.18 & .37 & .04 & .49 & .32 & .44 & -.71 & .51 & .30 & .15 & -.31 & & & & \\
\hline 14. Social curiosity & .12 & .13 & .14 & .28 & .02 & -.01 & -.05 & .23 & .11 & .57 & .26 & .35 & -.23 & & & \\
\hline 15. Thrill seeking & .06 & .17 & .03 & .06 & .00 & -.41 & -.18 & .06 & .39 & .69 & .32 & .17 & .04 & .32 & & \\
\hline 16. Uncertainty intolerance & .27 & .18 & -.34 & -.06 & -.44 & -.34 & -.28 & .68 & -.46 & -.23 & -.13 & .32 & -.85 & .26 & -.09 & \\
\hline 17. Ambiguity tolerance & -.15 & -.12 & .49 & .22 & .54 & .26 & .16 & -.48 & .49 & .49 & .40 & -.03 & .69 & -.10 & .31 & -.78 \\
\hline
\end{tabular}

Note. Italics indicates $p<.05$. bold indicates $p<.01$.

3.2.2 Openness/intellect, curiosity, and informationseeking. In contrast to our hypotheses, but consistent with Study 1, openness/intellect did not significantly correlate with information-seeking, either at the domain level $(r=-.05,95 \%$ CI $[-.16, .06])$ or the aspects openness $(r=.02)$ or intellect $(r=-.08)$. In addition, a Bayes factor regression indicated that the data were 5.59 times more likely to occur under the null hypothesis than under the alternative hypothesis, providing substantial evidence for a null effect of openness/intellect predicting informationseeking (Jeffreys, 1939/1961).

Next, supporting our predictions, we found that curiosity sub-scales deprivation sensitivity and joyous exploration each positively related to information-seeking (deprivation sensitivity $r=.20,95 \%$ CI $[.09, .31]$ ); joyous exploration $r=.15,95 \%$ CI $[.04, .26])$. However, in contrast to Study 1 , curiosity as a whole did not significantly correlate with information-seeking $(r=.09,95 \%$ CI [-.02, $.20]$ ). This was likely due to the moderate and negative correlation between information-seeking and the curiosity sub-scale stress tolerance ( $r=-.21,95 \%$ CI [-.32, -.10]). Indeed, when computing curiosity as a latent variable, it became a significant positive predictor of informationseeking (see Table S3.1). This appeared to be due to the poor loading of stress tolerance on a general curiosity factor: the model evidently reduced the negative effect that stress tolerance was playing on predicting informationseeking, allowing the remaining sub-scales to display their positive effect on information-seeking. Thus, with the exception of stress tolerance, curiosity was positively associated with information-seeking in Study 2.

3.2.3 Uncertainty attitudes, neuroticism, and information-seeking. Contrary to our predictions, information-seeking correlated significantly with uncertainty intolerance $(r=.27,95 \%$ CI $[.16, .37])$ and neuroticism ( $r=.13,95 \%$ CI $[.02, .24])$, and correlated negatively with ambiguity tolerance $(r=-.15,95 \%$ CI [-.26, -.04]). Similarly, Bayes factors revealed substantial evidence in favor of associations between informationseeking and ambiguity tolerance $\left(\mathrm{B}_{10}=3.46\right)$ and intolerance of uncertainty $\left(B_{10}=4898.79\right)$, whereas there was indeterminate evidence for a relation between neuroticism and information-seeking $\left(\mathrm{B}_{10}=1.53\right.$ in favor of the alternative). This indicates that participants who were more intolerant of uncertainty were more likely to pay in time to view the informative option.

3.2.4 Reward-related information-seeking. We next examined our single-item information-seeking measure that allowed participants to remove uncertainty about an upcoming reward. We predicted that we would observe similar information-seeking relations found by prior research using this version of the task (i.e., a positive relation with intolerance of uncertainty and neuroticism, and no measurable relation to openness/intellect). Supporting the first predictions, reward-related information-seeking significantly correlated with intolerance of uncertainty $(r=.18,95 \%$ CI $[.07, .29])$, ambiguity tolerance $(r=-.12,95 \%$ CI $[-.23,-.01])$, and neuroticism $(r=.12,95 \% \mathrm{CI}[.01, .23])$. A Bayes factor regression comparing a model in which each variable predicted information-seeking to a model in which there was no relationship found evidence that intolerance of uncertainty predicted information-seeking $\left(\mathrm{B}_{10}=16.07\right.$ in favor of predicting information-seeking), and anecdotal evidence for ambiguity tolerance $\left(\mathrm{B}_{10}=1.21\right)$ and neuroticism $\left(B_{10}=1.12\right)$. Note that these effect sizes are on par or less than those observed from our main information-seeking task, indicating that we do not have evidence that our modified task more strongly elicited intolerance of uncertainty. That said, the relation between curiosity and information-seeking was absent for the altered task: neither joyous exploration nor deprivation sensitivity correlated with seeking advance information about an uncertain outcome, and Bayes factor regressions indicated substantial evidence for a null relation (deprivation sensitivity $\mathrm{B}_{01}=4.14$; joyous exploration $\mathrm{B}_{01}$ = 3.79).

Finally, in contrast to our prediction that openness/intellect would not relate to the choice to see uncertainty-reducing information, a negative correlation was observed ( $r=-.16,95 \%$ CI [-.27, -.05]). This appeared to be driven primarily by the intellect aspect $(r=-.16)$, suggesting that individuals higher in intellect were more likely to wait until the end of the study to see their bonus 
payment. Convergent results were found with a Bayes factor regression: openness/intellect negatively predicted information-seeking $\left(\mathrm{B}_{10}=5.90\right)$, but assessing aspects, evidence for the alternative was substantial for intellect $\left(\mathrm{B}_{10}=5.51\right)$, whereas indeterminate evidence for a null effect was found for openness $\left(\mathrm{B}_{01}=1.86\right)$.

3.2.5 Exploratory Analyses. To further explore combinations of variables that may relate to seeking information, we conducted a Bayesian model comparison predicting our original 6-item information-seeking measure from openness/intellect, joyous exploration, deprivation sensitivity, ambiguity tolerance, and uncertainty intolerance. We followed the guidelines of Rouder and Morey (2012) and compared each predictor in turn, followed by all combinations of predictors. The Supplementary Information contains figures and exact numerical values for each predictive model.

The model with the highest evidence was given by the predictors joyous exploration and uncertainty intolerance, indicating that this model was 208,067 times more likely than a null model. Sampling from the posterior distribution of this model in order to obtain parameter estimates of regression slopes, each predictor was positively related to seeking information (joyous exploration $\mu=0.10,95 \%$ Credible Interval [0.04, 0.15]; intolerance of uncertainty $\mu=0.13,95 \%$ Credible Interval $[0.08,0.17]$ which converges with a traditional frequentist multiple regression finding that both of these are significant predictors of information-seeking (joyous exploration $\beta=0.19, t(298)=3.45, p<.001$; intolerance of uncertainty $\beta=0.29, t(298)=5.26, p<.001)$. The second highest performing model (joyous exploration, intolerance of uncertainty, and openness/intellect) was not a substantially worse performer $\left(\mathrm{BF}_{10}=0.73\right)$. However, given that the additional predictor did not result in a better fitting model, the former model could be favored on grounds of parsimony. All other models were considered substantially worse (all $\mathrm{BF}_{10}<0.33$ ). Note that for the second highest performing model, openness/intellect was a negative predictor of information-seeking $(\mu=-0.10$, 95\% Credible Interval $[-0.21,-0.02])$ whereas the other variables were positive predictors.

Given the well-documented links among openness/intellect, uncertainty intolerance, and curiosity, we were interested to observe the evidence for these variables as predictors of openness/intellect. We thus performed an additional Bayes factor model comparison predicting openness/intellect from joyous exploration, deprivation sensitivity, intolerance of uncertainty, and 6item information-seeking. The model with the greatest evidence was comprised of joyous exploration and intolerance of uncertainty $\left(\mathrm{M}_{10}=1.05 \mathrm{e}+37\right)$, the same two variables that formed the highest performing model predicting information-seeking. However, whereas both variables were positive predictors of information-seeking, joyous exploration was a positive predictor of openness/intellect $(\mu=0.38, \mathrm{SD}=.03,95 \%$ Credible Interval $[0.32,0.44])$ but intolerance of uncertainty was a negative predictor $(\mu=-0.15, \mathrm{SD}=0.02,95 \%$ Credible Interval $[-0.20,-0.10])$. This suggests that one reason openness/intellect was unrelated to information-seeking in our study is because it relates positively to one driver of information-seeking and negatively to another.

\section{General Discussion}

The information-seeking theory of openness/intellect proposes that openness/intellect is grounded in greater sensitivity to the reward value of information and should, therefore, predict informationseeking behavior (DeYoung, 2013). We tested this theory by investigating whether openness/intellect predicted the choice to pay a time cost to view non-instrumental information. Across two studies, individuals high in openness/intellect were no more likely to choose to view this form of information than their less open counterparts. However, curiosity predicted information-seeking in both studies, and intolerance of uncertainty predicted information-seeking in Study 2. To our knowledge, this is the first time that trait curiosity has been found to relate to information-seeking. Because curiosity and intolerance of uncertainty relate in opposite ways to openness/intellect, their associations with information-seeking may help account for the lack of such an association at the broader openness/intellect domain. Thus, our findings may help to refine DeYoung's (2013) information-seeking theory.

\subsection{Is the Information-Seeking Theory of Openness/Intellect Supported?}

Information-seeking is sometimes mentioned in definitions of openness/intellect (e.g., Allen \& DeYoung, 2017; DeYoung, 2015a; 2015b), giving the appearance that DeYoung's (2013) theory has been long since supported. However, there has been little research that has directly measured information-seeking. To address this, we adapted a task from decision science assessing willingness to pay for non-instrumental information (Bennett et al., 2016). In an effort to reduce any motivation driven by intolerance of uncertainty, information within this task did not inform participants of an upcoming event or outcome. Instead, participants first learned if they had won a reward and were then asked if they would like to see some information that did not affect any outcome.

Some might argue that the information in this task is too trivial to capture individual differences in openness/intellect. But this triviality is exactly the point: If individuals higher in openness/intellect have a preference to know things that they didn't already know, then this should be evident regardless of the form of information. These stimuli allow for a strong test of the theory: if we found that openness/intellect predicts seeking even this form of information, this would have provided compelling evidence that open individuals have a general-purpose sensitivity to any sort of new information. Conversely, demonstrating that open individuals are motivated to view artworks or intellectual materials could simply reflect the content of the openness/intellect scale items.

Consistent with Smillie (2019), we found no relation between openness/intellect and informationseeking in either study, with substantial evidence for a null effect obtained in Study 2. However, in both studies, 
curiosity-arguably a lower-level facet of the broader openness/intellect domain-positively predicted seeking information. Moreover, in Study 2, we observed that uncertainty intolerance positively predicted informationseeking. ${ }^{3}$ At the same time, consistent with prior research (Jach \& Smillie, 2019; Kashdan et al., 2018), we found that these traits were both strongly related to openness/intellect, but in opposite directions: openness/intellect was negatively related to uncertainty intolerance, but was strongly positively related to trait curiosity. The difference between the domain-level and facet level associations aligns with research showing that constructs measured at different levels of the trait hierarchy can produce unexpected results compared to when these are measured on the same level (Kretzschmar et al., 2018). If trait associations are specific to only particular facets or aspects of a trait, it might then be inappropriate to generalize these associations to the broader trait as a whole (Mõttus, 2016). Thus, the present finding suggest a potential refinement to DeYoung's (2013) information-seeking theory of openness/intellect, in that it may apply more narrowly to a specific facet of this domain (curiosity), but perhaps not to the domain more broadly.

In summary, the most straightforward version of the theory (i.e., higher openness/intellect leads to more information-seeking) was not supported by our results. However, restricted support for the theory could be found via its relation to curiosity. Of course, as we did not preregister this precise prediction, future studies are necessary to confirm these results.

\subsection{Future Research}

One important implication of our results is that the task and stimuli used to measure information-seeking matters: In both of our studies, curiosity predicted seeking information about inconsequential task details, but when the information reduced uncertainty about an upcoming reward, curiosity no longer predicted informationseeking, and openness/intellect became a negative predictor. If curiosity is the process via which openness/intellect relates to information-seeking, then we might observe a relation between openness/intellect and information-seeking if we could find stimuli that elicit feelings of curiosity much more strongly than uncertainty. One promising option is to use trivia questions. Many studies have shown that state curiosity predicts paying a cost to see answers to trivia questions (Kang et al., 2009; Gruber et al., 2014; Ligneul et al., 2018; Marvin \& Shohamy, 2016), but no study has assessed if state curiosity relates to trait curiosity or openness/intellect, or how this may in turn predict information-seeking preferences. Recently, a rich, normed database of trivia questions has been made available to researchers (Fastrich, Kerr, Castel, \& Murayama, 2018), providing an opportunity for future research to investigate these questions. An additional advantage of trivia questions is the ability to measure learning, thereby connecting information-seeking findings to theories of how openness/intellect relates to intelligence and knowledge acquisition (e.g., von Stumm, 2018; Ziegler et al., 2018).

An additional approach could be an informationseeking intervention measured with experience sampling (Scollon, Prieto, \& Diener, 2009). These methods have been used to assess interests in everyday life (Ziegler et al., 2018), and could be built on by explicitly asking participants to seek information in their everyday life, examining potential effects of self-reported (or otherreported) openness/intellect throughout the intervention. If curiosity-driven information-seeking underlies openness/intellect, then upregulating informationseeking should theoretically lead to increased openness/intellect-particularly if participants are instructed to seek information via fascination (i.e., joyous exploration) rather than to reduce their anxiety at not knowing (intolerance of uncertainty). Experience sampling approaches have been previously used to assess the causal structure between extraversion and positive affect (Jacques-Hamilton, Sun, \& Smillie, 2019), and processes that may drive volitional personality change (Hudson \& Fraley, 2015), giving some precedence to this technique.

Finally, rather than upregulating curiosity, future information-seeking paradigms could attempt to hold constant uncertainty, or yoke uncertainty to information such that gains in information entail increases in uncertainty. This may seem a formidable goal, given that information is often equated with reductions in uncertainty by definition (e.g., Shannon, 1948; Bennett et al., 2016; Gottlieb, Oudeyer, Lopes, \& Baranes, 2013). However, it is common for real-world information gains to accompany increases in uncertainty. Learning something can make you less certain about a prior belief (for example, when reading a murder mystery, new evidence can come to light that makes you unsure about your previous suspect), and uncertainty can immediately follow information-gain (this new evidence can make you question the motives of the other characters in the novel). This connects to existing ideas and research surrounding openness/intellect. DeYoung (2013) proposed that temporary increases in uncertainty can be rewarding to some individuals, as exploring uncertainty may lead to long-term knowledge acquisition and understanding (i.e., an ultimate decrease in uncertainty, even if there are many short-term increases). Relatedly, Mussel (2013) proposed that personality traits related to intellectual achievements (including the intellect aspect of openness/intellect) are underpinned by dual motivations to seek and conquer information, where seeking involves exploring complex stimuli (i.e., engaging in temporary increases of uncertainty) before attempting to understand and thus conquer that stimuli (i.e., reducing uncertainty). Openness/intellect is also associated with more positive relations between the emotions of interest and confusion

\footnotetext{
${ }^{3}$ Why did uncertainty intolerance continue to relate to informationseeking in Study 2? Although participants were no longer uncertain about whether they had won or lost the game, they nevertheless remained uncertain about the specific piece of information that they could learn about that game. If attitudes to uncertainty concern
}

anything that is unknown (Carleton et al., 2007), the knowledge that some currently unknown piece of information could be obtained may have led to uncertainty-motivated information-seeking, even when the information was irrelevant to their monetary outcome. 
(Fayn, Silvia, Dejonckheere, Verdonck, \& Kuppens, 2019). As confusion may arise from uncertainty, this suggests that individuals higher in openness/intellect may be better able to stay interested when exploring uncertain, confusing stimuli. We might thus expect curiosity and openness/intellect to relate to information-seeking when uncertainty increases, whereas individuals who are intolerant of uncertainty might be unlikely to seek information that also increases uncertainty. A multi-trial experimental paradigm that can measure the objective and subjective uncertainty in the environment would be highly valuable to test this basic hypothesis, link to prior ideas, and ultimately further refine the information-seeking theory of openness/intellect.

\subsection{Limitations}

The primary limitation of the current studies is the use of cross-sectional designs from which we are attempting to draw evidence of causal mechanisms. Specifically, we have conceptualized curiosity and intolerance of uncertainty as mechanisms that cause people to seek information, and potentially explain why the broad openness/intellect domain may not directly relate to information-seeking. This is obviously not an inference that we can make given the nature of our variables. However, conducting such correlation-based research was a necessary first step toward gathering evidence for these hypotheses. If we did not observe any relation between curiosity and information-seeking, or between intolerance of uncertainty and informationseeking, that would suggest that our theorizing was not correct (Underwood, 1975). At the least, we have found that our results are not inconsistent with our theoretical conceptions and have paved the way for future studies, as suggested above.

An additional limitation concerns the small number of trials used for our measure of informationseeking: 6 choices for our main measure, and only 1 for reward-related information-seeking. Although we obtained high reliability for our main measure, it would be valuable to confirm these findings using a version of our task with many more trials (as in Bennett et al., 2016; Brydevall et al., 2018). It would also be useful to add a measure of intelligence to any such study, given that some theories of intelligence propose bidirectional effects of fluid intelligence and openness on seeking out and acquiring knowledge (e.g., Ziegler et al., 2018).

Finally, although participants were explicitly told that information would not be useful in subsequent games, this doesn't ensure that they believed us. If participants believed information was instrumental, this could have increased reward-driven motivation to seek information and reduced the impact of uncertainty-driven and curiosity-driven motivation. It might be particularly likely for participants to be suspicious about the value of information for the last three games, which all concerned a similar storyline (a "gem quest"). However, if participants did believe that information was instrumental for those final three games, then we would expect to observe proportions of information-seeking that were higher for the penultimate and final game compared to the first. We didn't see this (Figure 2A), which may provide some reassurance that participants were following instructions as intended.

\section{Conclusion}

Openness/intellect-the putative trait of cognitive exploration-has itself been explored across multiple studies, but few direct tests of its proposed mechanistic underpinnings have been performed. To address this gap, we conducted some initial tests of the information-seeking theory of openness/intellect. We observed for the first time that trait curiosity, a facet of openness/intellect, predicted seeking non-instrumental information, and so too did intolerance of uncertainty. However, global openness/intellect did not predict choosing to view this form of information, perhaps because individuals scoring high on this trait tend to be both curious and tolerant of uncertainty. Our results thus fail to support any broad link between information-seeking and the openness/intellect domain. However, the relation between information/seeking and curiosity arguably provides some support for a restricted version of the theory. We hope that this study can spur future research to disentangle these interrelated constructs, and ultimately better understand the mechanistic underpinnings of curiosity, creativity, imagination, and exploration.

\section{References}

Allen, T. A., \& DeYoung, C. G. (2017). Personality neuroscience and the five factor model. In T. A. Widiger (Ed.), The Oxford handbook of the five factor model (pp. 319-352). New York, NY: Oxford University Press.

Antinori, A., Carter, O. L., \& Smillie, L. D. (2017). Seeing it both ways: Openness to experience and binocular rivalry suppression. Journal of Research in Personality, 68, 15-22.

Beaty, R. E., Kaufman, S. B., Benedek, M., Jung, R. E., Kenett, Y. N., Jauk, E., .. \& Silvia, P. J. (2016). Personality and complex brain networks: The role of openness to experience in default network efficiency. Human Brain Mapping, 37(2), 773-779.

Behrendt, S. (2014). lm.beta: Add Standardized Regression Coefficients to lm-Objects. $\mathrm{R}$

package version 1.5-1. Retrieved from https://CRAN.Rproject.org/package $=\mathrm{lm}$.beta

Belke, B., Leder, H., Strobach, T., \& Carbon, C. C. (2010). Cognitive fluency: High-level processing dynamics in art appreciation. Psychology of Aesthetics, Creativity, and the Arts, 4(4), 214.

Bennett, D., Bode, S., Brydevall, M., Warren, H., \& Murawski, C. (2016). Intrinsic valuation of information in decision making under uncertainty. PLoS Computational Biology, 12(7).

Bennett, D., Sutcliffe, K., Tan, N. P. J., Smillie, L. D., \& Bode, S. (2019). Anxious and obsessive-compulsive traits are independently associated with valuation of non-instrumental information. BioRxiv. doi:10.1101/768168

Blanchard, T. C., Hayden, B. Y., \& Bromberg-Martin, E. S. (2015). Orbitofrontal cortex uses distinct codes for different choice attributes in decisions motivated by curiosity. Neuron, 85(3), 602-614.

Bromberg-Martin, E.S., and Hikosaka, O. (2009). Midbrain dopamine neurons signal preference for advance information about upcoming rewards. Neuron 63, 119-126. doi:10.1016/j.neuron.2009.06.009

Brydevall, M., Bennett, D., Murawski, C., \& Bode, S. (2018). The neural encoding of information prediction errors during non- 
instrumental information seeking. Scientific Reports, 8(1), 6134. doi:10.1038/s41598-018-24566-X

Carleton, R. N., Mulvogue, M. K., Thibodeau, M. A., McCabe, R. E., Antony, M. M., \& Asmundson, G. J. (2012). Increasingly certain about uncertainty: Intolerance of uncertainty across anxiety and depression. Journal of Anxiety Disorders, 26(3), 468-479.

Carleton, R. N., Norton, M. P. J., \& Asmundson, G. J. (2007). Fearing the unknown: A short version of the Intolerance of Uncertainty Scale. Journal of Anxiety Disorders, 21(1), 105-117. doi:10.1016/j.janxdis.2006.03.014

Chamorro - Premuzic, T., Reimers, S., Hsu, A., \& Ahmetoglu, G. (2011). Who art thou? Personality predictors of artistic preferences in a large UK sample: The importance of openness. British Journal of Psychology, 100(3), 501-516.

Charpentier, C. J., Bromberg-Martin, E. S., \& Sharot, T. (2018). Valuation of knowledge and ignorance in mesolimbic reward circuitry. Proceedings of the National Academy of Sciences, 115(31), E7255-E7264.

Coxe, S., West, S. G., \& Aiken, L. S. (2009). The analysis of count data: A gentle introduction to Poisson regression and its alternatives. Journal of Personality Assessment, 91(2), 121-136.

Depue, R. A., \& Collins, P. F. (1999). Neurobiology of the structure of personality: Dopamine, facilitation of incentive motivation, and extraversion. The Behavioral and Brain Sciences, 22(3), 491-569. doi:10.1017/S0140525X99002046.

DeYoung, C. G. (2013). The neuromodulator of exploration: A unifying theory of the role of dopamine in personality. Frontiers in Human Neuroscience, 7, 762. doi:10.3389/fnhum.2013.00762

DeYoung, C. G. (2015a). Openness/intellect: A dimension of personality reflecting cognitive exploration. In M. Mikulincer, P. R. Shaver, M. L. Cooper, \& R. J. Larsen (Eds.), APA handbooks in psychology. APA handbook of personality and social psychology, Vol. 4. Personality processes and individual differences (pp. 369399). Washington, DC, US: American Psychological Association. doi:10.1037/14343-017

DeYoung, C. G. (2015b). Cybernetic big five theory. Journal of Research in Personality, 56, 33-58.

DeYoung, C. G., Grazioplene, R. G., \& Peterson, J. B. (2012). From madness to genius: The Openness/Intellect trait domain as a paradoxical simplex. Journal of Research in Personality, 46(1), 6378.

DeYoung, C. G., Peterson, J. B., \& Higgins, D. M. (2005). Sources of openness/intellect: Cognitive and neuropsychological correlates of the fifth factor of personality. Journal of Personality, 73(4), 825858.

DeYoung, C. G., Quilty, L. C., \& Peterson, J. B. (2007). Between facets and domains: 10 aspects of the Big Five. Journal of Personality and Social Psychology, 93(5), 880. doi:10.1037/0022-3514.93.5.880

DeYoung, C. G., Quilty, L. C., Peterson, J. B., \& Gray, J. R. (2014). Openness to experience, intellect, and cognitive ability. Journal of Personality Assessment, 96(1), 46-52.

Dienes, Z. (2014). Using Bayes to get the most out of non-significant results. Frontiers in Psychology, 5, 781.

Fastrich, G. M., Kerr, T., Castel, A. D., \& Murayama, K. (2018). The role of interest in memory for trivia questions: An investigation with a large-scale database. Motivation Science, 4(3), 227.

Fayn, K., Silvia, P. J., Dejonckheere, E., Verdonck, S., \& Kuppens, P. (2019). Confused or curious? Openness/intellect predicts more positive interest-confusion relations. Journal of Personality and Social Psychology, 117(5), 1016-1033.

Gosling, S. D., Ko, S. J., Mannarelli, T., \& Morris, M. E. (2002). A room with a cue: personality judgments based on offices and bedrooms. Journal of Personality and Social Psychology, 82(3), 379.

Gottlieb, J., Oudeyer, P. Y., Lopes, M., \& Baranes, A. (2013). Information-seeking, curiosity, and attention: computational and neural mechanisms. Trends in Cognitive Sciences, 17(11), 585593.
Gruber, M. J., Gelman, B. D., \& Ranganath, C. (2014). States of curiosity modulate hippocampus-dependent learning via the dopaminergic circuit. Neuron, 84(2), 486-496.

Hudson, N. W., \& Fraley, R. C. (2015). Volitional personality trait change: Can people choose to change their personality traits? Journal of Personality and Social Psychology, 109(3), 490.

Jach, H. K., \& Smillie, L. D. (2019). To fear or fly to the unknown: Tolerance for ambiguity and Big Five personality traits. Journal of Research in Personality, 79, 67-78. doi:10.1016/j.jrp.2019.02.003

Jacques-Hamilton, R., Sun, J., \& Smillie, L. D. (2019). Costs and benefits of acting extraverted: A randomized controlled trial. Journal of Experimental Psychology: General, 148(9), 1538.

Jeffreys, H. (1939/1961). The theory of probability. 1st/3rd Edn. Oxford, England: Oxford University Press.

John, O. P., \& Srivastava, S. (1999). The Big Five trait taxonomy: History, measurement, and theoretical perspectives. In L. A. Pervin \& O. P. John (Eds.), Handbook of personality: Theory and research (pp. 102-138). Guilford Press.

Jost, J. T., Glaser, J., Kruglanski, A. W., \& Sulloway, F. J. (2003). Political conservatism as motivated social cognition. Psychological Bulletin, 129(3), 339.

Kang, M. J., Hsu, M., Krajbich, I. M., Loewenstein, G., McClure, S. M., Wang, J. T. Y., \& Camerer, C. F. (2009). The wick in the candle of learning: Epistemic curiosity activates reward circuitry and enhances memory. Psychological Science, 20(8), 963-973.

Kashdan, T. B., Rose, P., \& Fincham, F. D. (2004). Curiosity and exploration: Facilitating positive subjective experiences and personal growth opportunities. Journal of Personality Assessment, 82(3), 291-305.

Kashdan, T. B., Gallagher, M. W., Silvia, P. J., Winterstein, B. P., Breen, W. E., Terhar, D., \& Steger, M. F. (2009). The curiosity and exploration inventory-II: Development, factor structure, and psychometrics. Journal of Research in Personality, 43(6), 987-998.

Kashdan, T. B., \& Steger, M. F. (2007). Curiosity and pathways to wellbeing and meaning in life: Traits, states, and everyday behaviors. Motivation and Emotion, 31(3), 159-173.

Kashdan, T. B., Stiksma, M. C., Disabato, D. J., McKnight, P. E., Bekier, J., Kaji, J., \& Lazarus, R. (2018). The five-dimensional curiosity scale: Capturing the bandwidth of curiosity and identifying four unique subgroups of curious people. Journal of Research in Personality, 73, 130-149. doi:10.1016/j.jrp.2017.11.011

Kaufman, S. B., Quilty, L. C., Grazioplene, R. G., Hirsh, J. B., Gray, J. R., Peterson, J. B., \& DeYoung, C. G. (2016). Openness to experience and intellect differentially predict creative achievement in the arts and sciences. Journal of Personality, 84(2), 248-258. doi:10.1111/jopy.12156

Kobayashi, K., Ravaioli, S., Baranès, A., Woodford, M., \& Gottlieb, J. (2019). Diverse motives for human curiosity. Nature Human Behaviour. doi:10.1038/s41562-019-0589-3

Kraaykamp, G., \& Van Eijck, K. (2005). Personality, media preferences, and cultural participation. Personality and Individual Differences, 38(7), 1675-1688.

Kretzschmar, A., Spengler, M., Schubert, A. L., Steinmayr, R., \& Ziegler, M. (2018). The relation of personality and intelligence-What can the Brunswik symmetry principle tell us? Journal of Intelligence, 6(3), 30.

Ligneul, R., Mermillod, M., \& Morisseau, T. (2018). From relief to surprise: Dual control of epistemic curiosity in the human brain. NeuroImage, 181, 490-500.

Lowenstein, G. (1994). The psychology of curiosity: A review and reinterpretation. Psychological Bulletin, 116(1), 75-98.

Lydon-Staley, D. M., Zhou, D., Blevins, A. S., Zurn, P., \& Bassett, D. S. (2019). Hunters, busybodies, and the knowledge network building associated with curiosity. PsyArXiv. doi:10.31234/osf.io/undy4

Marvin, C. B., \& Shohamy, D. (2016). Curiosity and reward: Valence predicts choice and information prediction errors enhance learning. Journal of Experimental Psychology: General, 145(3), 266. 
McCrae, R. R. (1987). Creativity, divergent thinking, and openness to experience. Journal of Personality and Social Psychology, 52(6), 1258.

McCrae, R. R., \& Costa Jr, P. T. (1997). Conceptions and correlates of openness to experience. In Handbook of personality psychology (pp. 825-847). Academic Press.

McLain, D. L. (2009). Evidence of the properties of an ambiguity tolerance measure: The multiple stimulus types ambiguity tolerance scale-II (MSTAT-II). Psychological Reports, 105(3), 975-988. https://doi.org/10.2466/pr0.105.3.975-988.

Morey, R. D., \& Rouder, J. N. (2018). BayesFactor: Computation of Bayes Factors for Common Designs. R package version 0.9.12-4.2. https://CRAN.R-project.org/package=BayesFactor

Mõttus, R. (2016). Towards more rigorous personality trait-outcome research. European Journal of Personality, 30(4), 292-303.

Mussel, P. (2013). Intellect: A theoretical framework for personality traits related to intellectual achievements. Journal of Personality and Social Psychology, 104(5), 885.

Pickering, A. D., \& Gray, J. A. (2001). Dopamine, appetitive reinforcement, and the neuropsychology of human learning: An individual differences approach. In A. Eliasz, \& A. Angleitner (Eds.). Advances in research on temperament (pp. 113-149). Lengerich: PABST Science Publishers.

Rammsayer, T. H. (1998). Extraversion and dopamine: Individual differences in respon- siveness to changes in dopaminergic activity as a possible biological basis of extra- version. European Psychologist, 3, 37-50.

Rentfrow, P. J., \& Gosling, S. D. (2003). The do re mi's of everyday life: the structure and personality correlates of music preferences. Journal of Personality and Social Psychology, 84(6), 1236.

Revelle, W. (2018) psych: Procedures for Personality and Psychological Research,

Northwestern University, Evanston, Illinois, USA. Retrieved from https://CRAN.R-project.org/package=psych

Rosseel, Y. (2012). lavaan: An R Package for Structural Equation Modeling. Journal of Statistical Software, 48(2), 1-36.

Rouder, J. N., \& Morey, R. D. (2012). Default Bayes factors for model selection in regression. Multivariate Behavioral Research, 47(6), 877-903. doi:10.1080/00273171.2012.734737

Schwaba, T. (2019). The structure, measurement, and development of openness to experience across adulthood. In D. P. McAdams, R. L. Shiner, and Jennifer L. Tackett (Eds.), Handbook of personality development. Guilford Publications.

Scollon, C. N., Prieto, C. K., \& Diener, E. (2009). Experience sampling: promises and pitfalls, strength and weaknesses. In E. Diener (Ed.), Assessing well-being (pp. 157-180). Springer, Dordrecht.

Shannon, C. E. (1948). A mathematical theory of communication. Bell System Technical Journal, 27(3), 379-423. doi:10.1002/j.15387305.1948.tb01338.x

Smillie, L. D. (2019). Does openness/intellect predict dopaminergic non-instrumental information-seeking? Symposium talk presented at the World Conference on Personality, Hanoi, Vietnam.

Soto, C. J., \& John, O. P. (2017). The next Big Five Inventory (BFI-2): Developing and assessing a hierarchical model with 15 facets to enhance bandwidth, fidelity, and predictive power. Journal of Personality and Social Psychology, 113(1), 117.

Stanley, D. (2018). apaTables: Create American Psychological Association (APA) Style

Tables. R package version 2.0.5. Retrieved from https://CRAN.Rproject.org/package=apaTables3

Silvia, P. J., Nusbaum, E. C., Berg, C., Martin, C., \& O'Connor, A. (2009). Openness to experience, plasticity, and creativity: Exploring lower-order, high-order, and interactive effects. Journal of Research in Personality, 43(6), 1087-1090.

Trapp, S., \& Ziegler, M. (2019). How Openness Enriches the Environment: Read More. Frontiers in Psychology, 10.

Van Eijck, K., \& de Graaf, P. M. (2004). The Big Five at school: The impact of personality on educational attainment. The Netherlands Journal of Social Sciences, 40(1), 24-40. von Stumm, S. (2018). Better open than intellectual: The benefits of investment personality traits for learning. Personality and Social Psychology Bulletin, 44(4), 562-573.

Westfall, J., \& Yarkoni, T. (2016). Statistically controlling for confounding constructs is harder than you think. PloS one, 11(3).

Wickham, H. (2017). tidyverse: Easily Install and Load the 'Tidyverse'. $\mathrm{R}$ package version 1.2.1. Retrieved from https://CRAN.R-project.org/package=tidyverse

Wilke, C. O. (2018). cowplot: Streamlined Plot Theme and Plot Annotations for 'ggplot2'. R

package version 0.9.3. Retrieved from https://CRAN.Rproject.org $/$ package $=$ cowplot

Woo, S. E., Chernyshenko, O. S., Longley, A., Zhang, Z. X., Chiu, C. Y., \& Stark, S. E. (2014). Openness to experience: Its lower level structure, measurement, and cross-cultural equivalence. Journal of Personality Assessment, 96(1), 29-45.

Yentes R.D., \& Wilhelm, F. (2018). careless: Procedures for computing indices of careless responding. $\mathrm{R}$ package version 1.1.3.

Ziegler, M., Schroeter, T. A., Lüdtke, O., \& Roemer, L. (2018). The enriching interplay between openness and interest: a theoretical elaboration of the OFCI model and a first empirical test. Journal of Intelligence, 6(3), 35. 